\title{
Wie viel medizinischen Fortschritt gab es in den letzten 25 Jahren?
}

\author{
Dr. med. Dirk \\ Einecke \\ Chefredakteur der \\ MMW-Fortschritte \\ der Medizin
}

— Es steht immer ganz klein und unscheinbar auf dem Heftrücken der MMW: 148. Jahrgang, 149. Jahrgang, 150. Jahrgang. Dieser geht nun zu Ende, die älteste und traditionsreichste medizinische Wochenschrift Deutschlands feiert 150-jähriges Bestehen. Anlass zu einer besonderen Jubiläumsausgabe, die Sie in den Händen halten. Das umfangreiche Heft gliedert sich in drei Teile:

\section{Die wesentlichen Fortschritte der letzten 25 Jahre}

Der Kern ist der Stärke der MMW gewidmet, der Fortbildung. MMW-Leser sind - so sagt es die Statistik - im Schnitt etwa 50 Jahre alt, vor ca. 25 Jahren haben viele ihr Staatsexamen abgelegt. Welchen medizinischen Fortschritt hat es seither gegeben? Eine brisante Frage voller gesundheitspolitischer Aktualität. Im Bestreben, eine bezahlbare Versorgung sicherzustellen, wird der medizinische Fortschritt von Politik und Medien immer öfter kleingeredet. Nicht viel passiert also in den letzten 25 Jahren? In 32 Beiträgen legen die MMWSchriftleiter der großen medizinischen Fächer Zeugnis vom Gegenteil ab. Eine gute Zusammenfassung all dessen, was sich seit dem Staatsexamen Anfang der 80er-Jahre getan hat! Seite 60 bis 176 .

\section{Die Sorgen der Leser}

Medizinisch auf dem Laufenden zu bleiben ist für viele Ärzte die Kür. Die Pflicht sieht anders aus: Bürokratie, sich vertraut machen mit ständig wechselnden Rahmenbedingungen, Einschränkungen der ärztlichen Freiheit. Was haben Gesundheitsreformen und Honorarreformen gebracht? Worauf muss sich der Arzt in den nächsten Jahren einstellen? Was kommt auf die Ärzte zu mit dem Gesundheitsfonds, den Versorgungszentren, den Individualverträgen? Geht sie weiter, die Ausbeutung der Ressource Arzt? Antworten in der Sektion „Der Hausarzt heute“, Seite 48 bis 59.

\section{Jahre MMW}

Zu Beginn jedoch ein Blick zurück auf 150 Jahre Medizingeschichte, begleitet durch die MMW, lange als Publikations-, nun als Fortbildungsorgan. Welche berühmten Autoren publizierten was in der MMW? Wie kam die Zeitschrift durch die Weltkriege, wie durch die Währungsreformen und nun durch die Gesundheitsreformen? Wem gehört sie eigentlich heute, die MMW? Wie kommen die Inhalte zustande, wie viele Ärzte lesen sie? Seite 8 bis 46 .

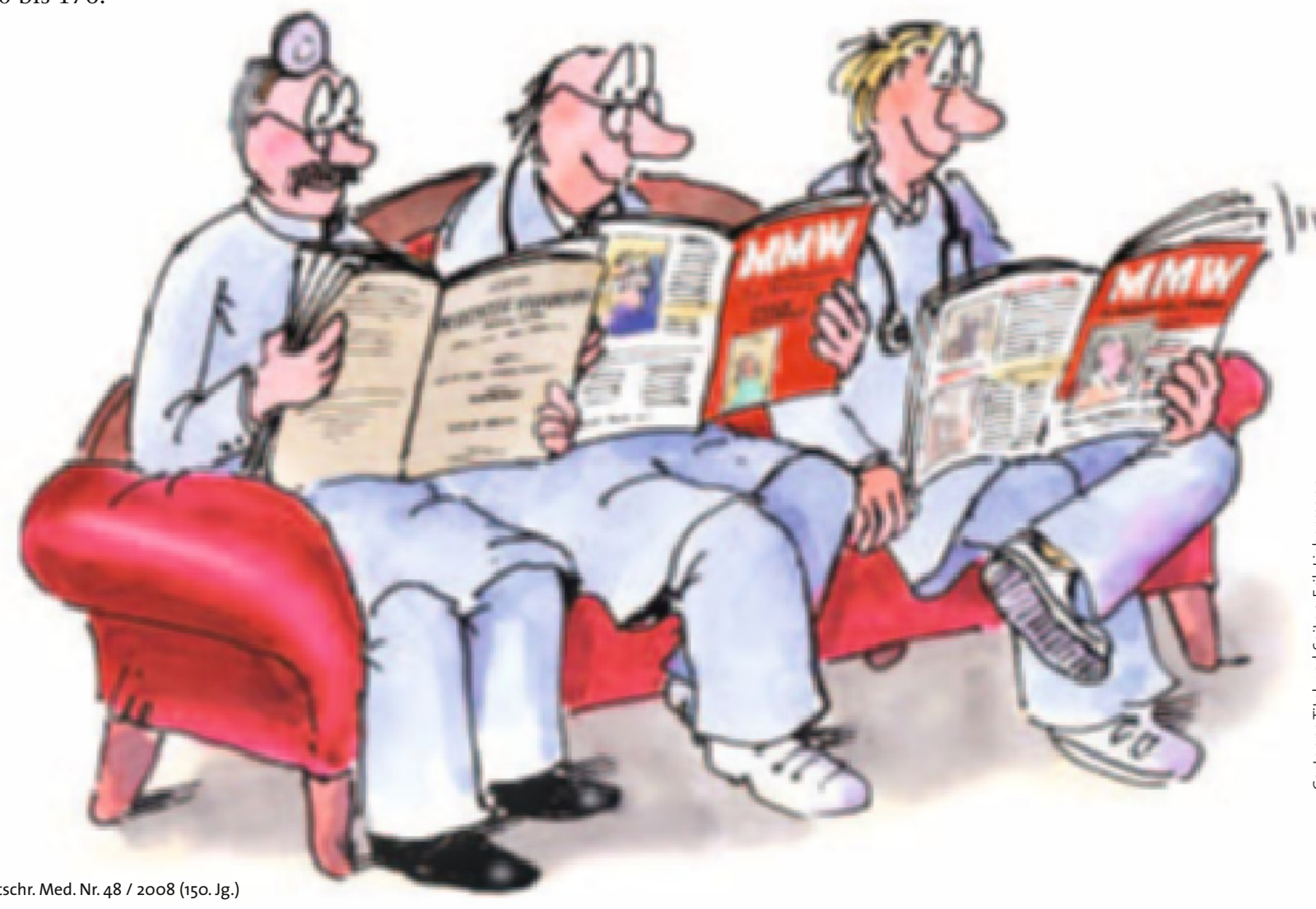

